\title{
O Clube de Gravura de Porto Alegre e o desejo de realizar uma arte para o povo
}

\author{
Talitha Bueno Motter \\ Universidade Federal do Rio de Janeiro
}

\section{Resumo}

O Clube de Gravura de Porto Alegre (CGPA) encontrou na cultura gaúcha sua principal temática. Seus membros vislumbravam no artista uma função social. Segundo Carlos Scliar (1954), um dos fundadores do Clube, o CGPA objetivava que suas gravuras fossem encontradas em todos os lares, para que assim transmitissem um conteúdo de confiança na vida e na luta do povo gaúcho. O presente artigo, a partir dos conceitos de arte popular abordados por Vázquez (2010) e Canclini (1984), reflete sobre as aproximações e afastamentos da produção do CGPA de uma arte verdadeiramente popular. Palavras-chave: Arte Popular, Gravura, Clube de Gravura de Porto Alegre.

\section{Abstract}

The Engraving Club of Porto Alegre ("Clube de Gravura de Porto Alegre," or "CGPA") adopted the gaucho culture as its main theme, and its members believed that artists have a social role. According to Carlos Scliar (1954), one of the Engraving Club's founders, the CGPA's main objective was to make their works present in all state's households, so that they could convey their confidence in the people's life and struggle. Based on the concepts of popular art developed by Vázquez (2010) and Canclini (1984), this paper discusses how well the CGPA's works reflected a truly popular art form.

Keywords: Popular Art, Engraving, Engraving Club of Porto Alegre.

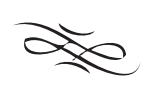




\section{Gravura: um caminho para popularizar a arte}

A técnica da gravura usualmente é associada a um caráter democrático por sua possibilidade de reprodução (ALVES, 2007), que permite estabelecer um custo baixo por cada impressão. O Clube de Gravura de Porto Alegre (1950-1956), inspirado no modelo do Taller da Gráfica Popular do México (SCARINCI, 1982), também vislumbrou na gravura um meio de popularizar a arte e de transmitir suas mensagens para um público mais amplo. Conforme texto de Carlos Scliar, um dos fundadores da agremiação, escrito para a revista Horizonte':

É propósito do Clube dos Amigos da Gravura não só o desenvolvimento dessas técnicas entre os nossos artistas, como a divulgação do gosto pela gravura entre camadas cada vez mais vastas de nosso povo. Pela sua própria técnica é a gravura, de todas as artes plásticas, a que está economicamente mais ao alcance do público. (SCLIAR, 1952, p. 1).

Porém, como afirma Aracy Amaral (1987), no caso dos clubes de gravura brasilei$\operatorname{ros}^{2}$, a circulação da produção estava limitada aos associados, e não ocorreu em grande escala como no México. Tal restrição prejudicou, em parte, o cumprimento do objetivo de aproximar a arte do povo, de forma que as ideias transmitidas possibilitassem um desenvolvimento social (ALVES, 2007).

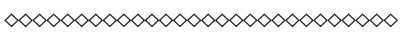

1 A revista Horizonte, periódico vinculado ao Partido Comunista Brasileiro, foi causa inicial da fundação do CGPA, em princípio chamado Clube dos Amigos da Gravura. Vasco Prado e Carlos Scliar, seus fundadores, receberam do Partido a tarefa de reorganizá-la, em conjunto com outros militantes, e para auxiliar no seu financiamento o Clube foi criado (GONÇALVES, 2005). Além desse auxílio, seus artistas contribuíram com muitas ilustrações para a revista.

2 No início dos anos de 1950, germinaram clubes de gravura em diversos locais do país. Além do CGPA, pode-se citar o Clube de Gravura de Bagé (RS, 1951), o Centro de Gravura do Paraná (1951), o Clube de Gravura de Santos (SP, 1951), o Clube de Gravura de São Paulo (1952), o Clube de Gravura de Recife (PE, 1953), ligado ao Atelier Coletivo de Recife (1952) e também o Clube de Gravura do Rio de Janeiro (c.1952). Suas atuações se assemelham, não só por causa da prática da gravura, mas pelo apoio recebido do PCB e, ainda, pela influência que o CGPA teve sobre a criação dos demais grupos.
} 


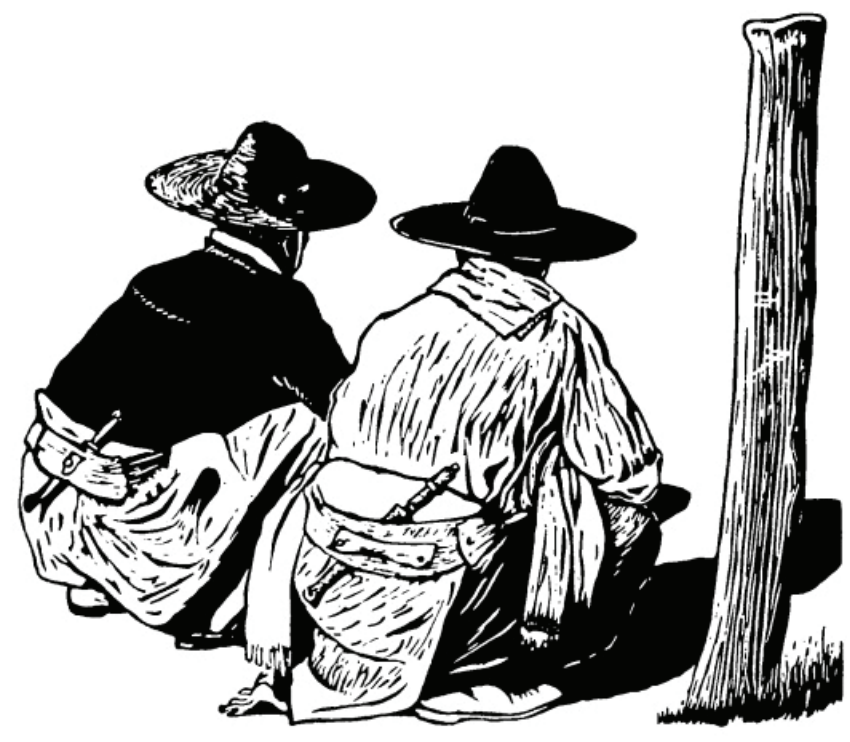

Figura 01 - Vasco Prado, Gaúchos acocorados, 1951, Linoleogravura, 14,6x17cm (GRAVURAS, 1952, p.6).

Mas, a temática, também foi uma forma de seus artistas buscarem essa proximidade, representando trabalhadores tanto do campo quanto da cidade, o cotidiano da campanha gaúcha ou mesmo sensibilizando a população para temas relativos à Campanha Mundial pela Paz ocorrida na Guerra Fria, por exemplo. Em artigo sobre o Salão da Associação Francisco Lisboa de 1951, na revista Horizonte, a inspiração na realidade local é destacada nas seções de Gravura, Desenho e Artes Gráficas, nas quais os integrantes do CGPA participaram, demonstrando essa preocupação já em 1951.

Demétrio Ribeiro (1951, p. 307), nesse mesmo texto, valoriza os artistas que "se aproximam da realidade que os cerca", e, dessa forma, do povo e coloca que o "artista revolucionário sente a necessidade de exprimir o que há de essencial no momento atual, o que há de novo, aquilo que distingue a nossa época das demais etapas da história”. Essa produção artística, preocupada em trazer os anseios do povo de uma época, relaciona-se com o conceito de arte popular, desenvolvido por Adolfo Sánchez Vázquez, filósofo e estudioso de Marx.

\section{Arte popular e o Clube de Gravura de Porto Alegre}

No livro “As ideias estéticas de Marx” (1ª ed. 1965, México), Adolfo Sánchez ressalta as possibilidades de mistificação do termo arte popular. Muitas vezes, essa expressão 
é associada à chamada arte de massas, uma arte inferior voltada para o lucro, e direcionada para o chamado homem-massa "despersonalizado, desumanizado, oco por dentro, esvaziado de seu conteúdo concreto e vivo, que pode se deixar modelar docilmente por qualquer manipulador de consciências" (VÁZQUEZ, 2010, p. 228). Para o antropólogo Néstor García Canclini (1984), arte para as massas é aquela produzida pela classe dominante, ou a serviço desta, a qual propaga a ideologia burguesa, proporciona lucros aos donos dos meios de difusão e possui como foco a sua distribuição.

Antonio Augusto Arantes, em "O que é cultura popular" (1984), diferencia a arte do povo, em que o artista não se distingue dos consumidores, de arte popular, a partir do "Anteprojeto do Manifesto do CPC" ${ }^{3}$. Nesse caso, o termo arte popular estaria associado ao conceito de arte de massas abordado por Vázquez, que objetiva "distrair o espectador em vez de formá-lo, entretê-lo e aturdi-lo, em vez de despertá-lo para a reflexão e a consciência de si mesmo" (MARTINS, 1979 apud ARANTES, 1984, p.53-54).

Cassandra Gonçalves, em sua dissertação "Clube de Gravura de Porto Alegre: Arte e Política na Modernidade" (2005), descreve o contexto histórico da década de 1950 do Rio Grande do Sul, trazendo o avanço dessa arte de massas. Pois, os ícones de consumo dos Estados Unidos, através, principalmente, da televisão, estabeleceram um processo de aculturação no país. Este processo se enfatizou a partir de meados da década de 1950, período no qual a televisão passa a ser amplamente disseminada entre os brasileiros. O regionalismo gaúcho é igualmente afetado, pois sofre um enfraquecimento. "A cultura de massa passou de roldão por cima do homem da campanha e do gaúcho heroico" (GONÇALVES, 2005, p.41), embora existissem iniciativas como a dos artistas do CGPA de trabalhar com elementos indenitários do gaúcho, ou mesmo eventos, como o $1^{\circ}$ Congresso Tradicionalista (1954, Santa Maria/RS) ${ }^{4}$.

Mas, as mitificações em relação à arte popular não param por aí, fazer arte popular também não é converter o povo em um objeto de representação (VÁZQUEZ, 2010). O povo é entendido aqui como diferente do homem de massa: "as massas e o povo se diferenciam radicalmente como [...] o desumanizado e o humano, o inerte e o vivo, o passivo e o ativo ou o criador" (VÁZQUEZ, 2010, p.254). A sua força fundamental é encontrada nas camadas trabalhadoras, que, ao estabelecerem uma consciência de classe, lutam para não serem tratadas como massas (VÁZQUEZ, 2010), de acordo com a afirmação de Canclini: $\mathrm{O}$ "povo inclui unicamente aqueles que alugam sua força de trabalho [...]" (1984, p.76).

As gravuras produzidas pelo Clube de Gravura de Porto Alegre, às vezes, pare-

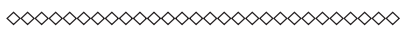

3 O Anteprojeto do Centro Popular de Cultura foi escrito por Carlos Estevam Martins, em 1962, e publicado em 1979, na Arte em Revista n¹ (São Paulo); estavam vinculados ao CPC, artistas e intelectuais que tinham "em vista dar uma contribuição para que o homem do povo pudesse superar [...] as enormes desvantagens que ele enfrenta para adquirir uma consciência adequada de sua real situação no mundo em que vive e trabalha" (MARTINS, 1980 apud ARANTES, 1984, p.55).

4 Em ocasião deste, o conjunto Tropeiros da Tradição (Porto Alegre), dirigido por Paixão Côrtes, organizou a Exposição de Pintura Gauchesca, com a colaboração do CGPA. 
cem remeter a este segundo engano sobre o que seria arte popular - a inserção do "povo" apenas através de sua imagem. Como é o caso de "Obra", de Gastão Hofstetter, que possui uma linguagem objetiva e acaba explorando pouco das possibilidades da gravura (Figura 02). Hofstetter retrata dois trabalhadores se alimentando, com uma construção ao fundo, a perspectiva linear está presente, mas não há a formação de texturas internas às formas, apenas no fundo, próximo à fiação elétrica, e um pouco no chão podem ser vistos os vestígios dos cortes sobre o linóleo. A denúncia da miséria dos obreiros é clara, seus pés estão descalços, alimentam-se mal; e mal pagos constroem as estruturas indicativas do progresso nas cidades - os prédios. Essa gravura é um dos exemplos que indicam a influência do realismo socialista na obra dos artistas da agremiação.

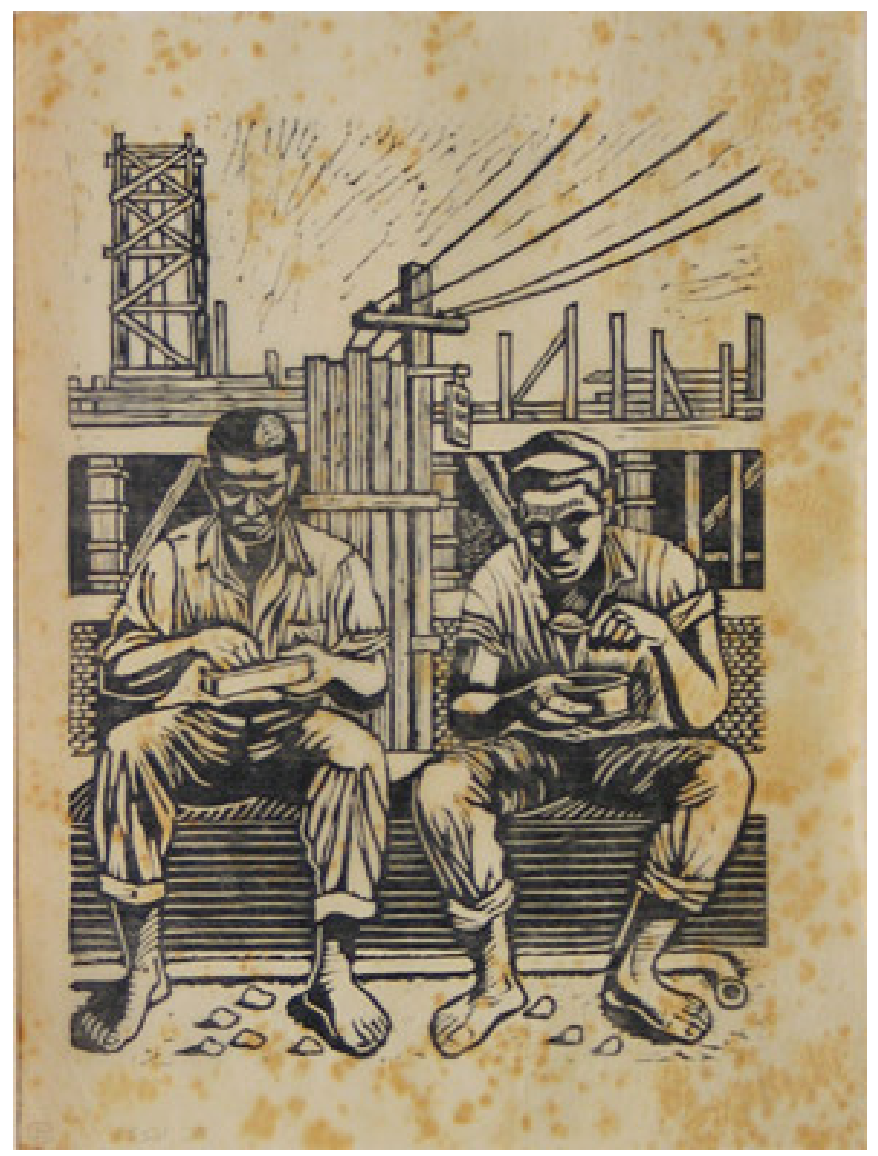

Figura 02 - Gastão Hofstetter, Obra, 1952, Linoleogravura, 31×22cm. Disponível em: < http://www.pinacoteca.org.br/>.

Segundo Vázquez (2010), o realismo socialista, surgido em meados dos anos de 1930, partiu do princípio de que o artista, dentro de uma concepção marxista-leninista, deveria assumir uma nova atitude diante do homem e das coisas; e a nova realidade só 
poderia ser refletida artisticamente se fosse vista através de novos olhos. Entretanto, a estética do realismo socialista estabeleceu-se com normas e modelos, e eliminou a possibilidade de experimentação formal. As obras realizadas a partir de seus preceitos deveriam ser acessíveis e didáticas, "funcionando em diversos aspectos como uma arma de publicidade e propaganda para a liderança política” (WOOD, 1998 apud GONÇALVES, 2005, p.59).

Carlos Scarinci chama a atenção para o fato de que o CGPA estava inserido em um contexto maior, no qual intelectuais do mundo inteiro seguiam as diretrizes do realismo socialista e objetivavam "uma arte voltada para o povo e para seus problemas, acreditando na eficácia instrumental da arte para mudanças da sociedade" (1982, p.102). Objetivos que concordam com a concepção de Canclini de uma obra de arte com caráter popular, o qual pode ser identificado na produção artística que expressa a "consciência compartilhada de um conflito" (CANCLINI, 1984, p.77) e que contribui para superá-lo.

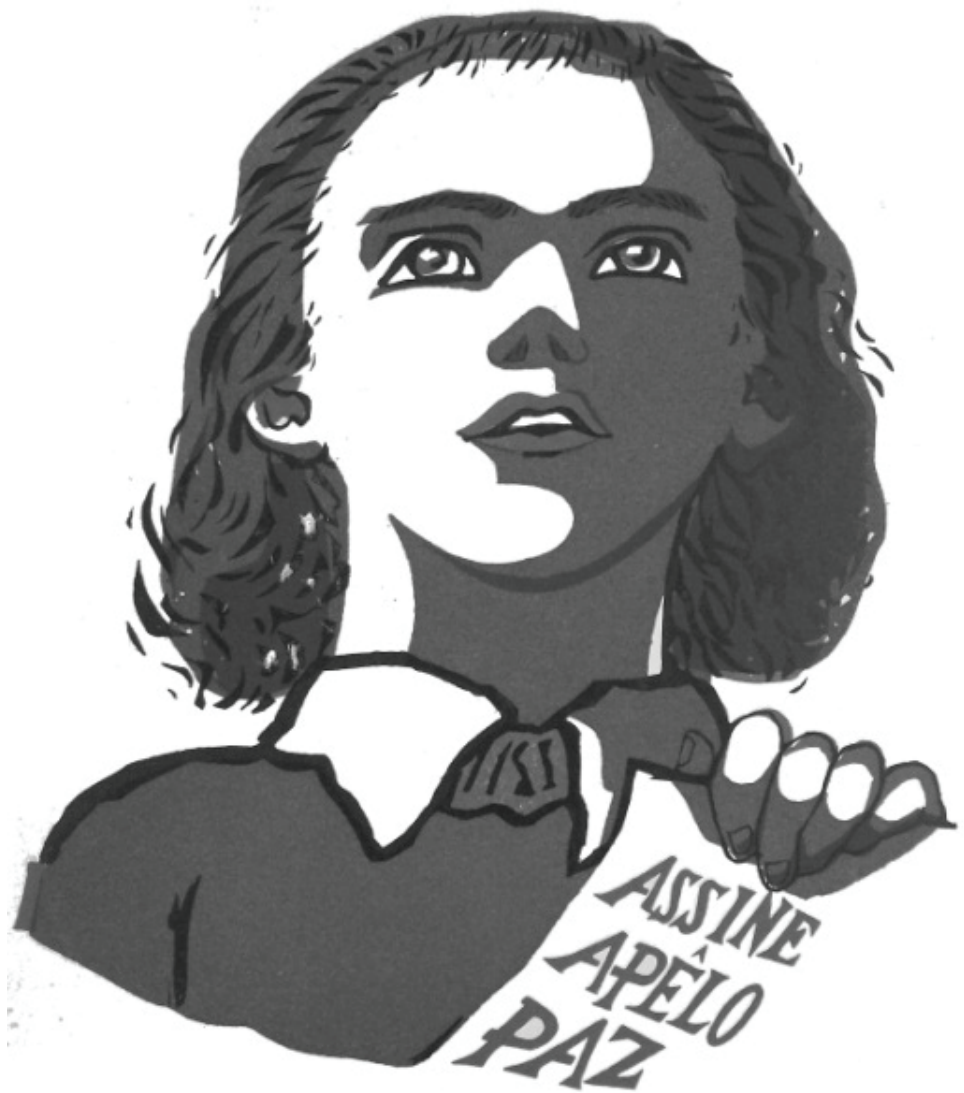

Figura 03 - Carlos Scliar, Assine o apelo, 1952, Linoleogravura, 24×21cm (GRAVURAS, 1952, p.35). Gravura capa da revista: Horizonte, Porto Alegre, Nova Fase, Ano II, n5, maio 1952. 
O Clube de Gravura de Porto Alegre durante a sua existência auxiliou na campanha de assinaturas por um pacto de paz, incentivada pelos partidos comunistas de diversos países. No período da Guerra Fria, a luta pela paz correspondia ao anseio de muitos, fato que se comprova com o número de 400 mil assinaturas obtidas em Porto Alegre, durante dois meses de campanha. A cidade, nessa ocasião, possuía um total de 800 mil habitantes (SCLIAR, 1982 apud AMARAL, 1987).

A arte popular estabelece uma relação com a política, pois expressa os interesses e aspirações de um povo, mas o artístico não deve se dissolver no político (VÁZQUEZ, 2010). A produção de gravuras realizadas com a temática da paz mundial foi ampla, assunto de acordo com as “aspirações de um povo". A exploração da linguagem da gravura, nesses casos, presou por uma representação direta com grande poder comunicativo, mas isso nem sempre significou a ausência do fator artístico, como no caso da gravura "Assine o apelo" de Carlos Scliar (Figura 03). A imagem é impactante e essa sensação é reforçada pelo alto contraste das cores, o verde marca a sombra sobre a face e o branco o lado direito do rosto. $\mathrm{O}$ olhar voltado para o alto impele o observador a assinar por um pacto de paz. Sobre essa imagem Diego Rivera (apud PONTUAL, 1970, p.87) declarou em 1953:

Quanta simplicidade! Que pureza de emoção! Ninguém se negará a assinar o apelo de Paz. Sente-se o ardor interior que impulsiona e isso aumenta a sua beleza plástica. Está aí um exemplo perfeito do papel da obra plástica com conteúdo político claro, singelo e forte.

A escolha por uma linguagem que possibilite a comunicação com um público maior pode, às vezes, significar o rebaixamento do valor estético da arte, o caminho mais fácil de conexão entre o povo e o artista. A arte, no entanto, não dever ser hermética, dirigindo-se a um público privilegiado (VÁZQUEZ, 2010). A produção artística denominada verdadeiramente popular não é nem de massas, nem minoritária, e sim

[...] para todos os homens que sentem a necessidade de uma apropriação humana das coisas e que encontrem na relação estética uma forma de satisfazer profundamente essa necessidade, e no objeto estético, uma utilidade humana. (VÀZQUEZ, 2010, p.246).

Conforme Canclini (1984), um dos indicadores falsos de arte popular é o número de espectadores.

O Clube de Gravura de Porto Alegre utilizou-se dos canais usuais para divulgação de sua produção, como salas de exposição e salões, assumindo nesse sentido um caráter 
elitista, porém suas gravuras eram igualmente promovidas pela revista Horizonte, e esta atingia um número maior de pessoas (AMARAL, 1987). Para baratear os clichês utilizados na impressão das imagens do periódico, os membros do clube optaram pelo uso do linóleo; aliás, a gravura original era o próprio clichê (HOLFELDT; MORAES; WEBSTER, 1976). Carlos Scliar declarou em depoimento à Aracy Amaral: "esclarecíamos o público indicando que eles podiam recortar aquela capa, que era uma gravura original, pela qualidade da estampa e, assim, a colecionasse” (1982 apud AMARAL, 1987, p. 184).

Em uma sociedade capitalista os meios de comunicação de massa não são controlados pelos artistas, não estando neles o caminho para a formação de um público capaz de usufruir obras de arte (VÁZQUEZ, 2010), nesse sentido, pode-se argumentar que a revista que propagava a produção dos artistas do Clube era de esquerda e por isso tinha essa abertura. A Guerra Fria, no entanto, caracterizou-se por um período de disputas ideológicas e no lado comunista, pela necessidade de dominação, também houve controle sobre as atividades artísticas.

Segundo Canclini, a arte popular é produzida pela classe trabalhadora, ou por aqueles artistas que representam seus interesses e objetivos. "Seu valor supremo é a representação e a satisfação solidária dos desejos coletivos" (1984, p.50). A arte popular está voltada aos anseios do homem de seu tempo, mas ela se alça para o universal devido a sua própria substância popular (VÁZQUEZ, 2010). "Fazer arte para o povo é fazer arte universal, é mergulhar na substância humana particular - nacional e popular - para dela sair carregado de universalidade" (VÁZQUEZ, 2010, p.235). As obras que seguem estes preceitos sobrevivem ao seu próprio tempo.

O Clube de Gravura buscou a realização de uma arte nacional, a qual segundo Carlos Scliar (1952) só poderia ser obtida através de temas nacionais. Para tanto, o conhecimento da realidade brasileira, e mais especificamente do povo gaúcho, fazia-se necessário. A aproximação de alguns artistas do CGPA ao homem do campo, através de viagens às estâncias gaúchas, estava de acordo com esse objetivo ${ }^{5}$. "Sem contato com a realidade, sem participação com aqueles temas que desejamos representar, não chegaremos senão a obras superficiais de curto alcance" (SCLIAR, 1954, p.25).

A série "Xarqueadas" de Danúbio Gonçalves, inspirada no romance homônimo, escrito por Pedro Wayne, pode exemplificar bem essa questão de tornar universal o particular. A atividade das charqueadas no final da década de 1940 já era quase inexistente (GONÇALVES, 2005), mas o seu caráter desumano não havia sido eliminado. Danúbio Gonçalves acercou-se de um grupo específico de trabalhadores e documentou procedimentos quase em extinção, mas que faziam parte daquela realidade. Os apontamentos, executados pelo artista, possibilitaram a elaboração das gravuras. Danúbio preocupado

$\infty<\infty<\times<\times<\times<\times<\times<\times<\times<\infty<\times<\infty$

5 Glauco Rodrigues, membro do CGPA, em uma carta para Carlos Scliar escreveu: "Um convite para ti: pega teu material - pintura, desenho, gravura - e vem para Bagé [...]. Aqui estamos indo todos os dias à xarqueada [...] é um tema que pelo que contém de verdade e de humano é exatamente o que procuramos" (1952 apud, CAVA et al, 2011). 
em aproximar-se do seu tema o transcendeu, tornando-o universal, já que, segundo Paulo Gomes, a série fala "a língua universal do trabalhador oprimido, sendo atemporal no seu espírito” (2004, p. 116).

O espírito épico, percebido por Gomes (2004), na série de gravuras de Danúbio, justifica-se na sobreposição do "eu” do artista pelo "nós”. No épico, há uma sensibilidade ao que acontece no mundo, "é o olhar individual, mas não a vivência pessoal, buscando figurar uma experiência que seja comum a todos os seres humanos" (GOMES, 2004, p. 115). Esse caráter estabelece a universalidade característica da arte verdadeiramente popular descrita por Vázquez (2010).

Na gravura "Manteiros" (Figura 04) está representado no primeiro plano um homem levando uma manta de carne nas costas e ao fundo existem duas figuras próximas vestindo uniforme, policiais que tinham a missão de manter a ordem na Charqueada (LEITE, 2011). A delimitação dos corpos é produzida basicamente a partir da linha preta, obtida pela retirada de madeira dos dois lados. Teixeira Coelho (2009), ao escrever sobre a técnica da gravura, ressalta a resistência do material como um fator determinante para essa linguagem, contudo sem um olhar minucioso, as cópias impressas, no caso da xilogravura de topo ${ }^{6}$, escondem a luta entre os buris e a madeira, eliminando aparentemente o esforço oriundo do processo. Um observador que desconheça essa batalha entre a matéria, que se faz viva nas suas imposições, e o desejo do artista, não deixará de perceber, nos charqueadores, uma metáfora dos esforços dos indivíduos que lutam diariamente pela sobrevivência. No entanto, a série "Xarqueadas" não pode sozinha atribuir o caráter de arte popular às produções do Clube de Gravura de Porto Alegre.

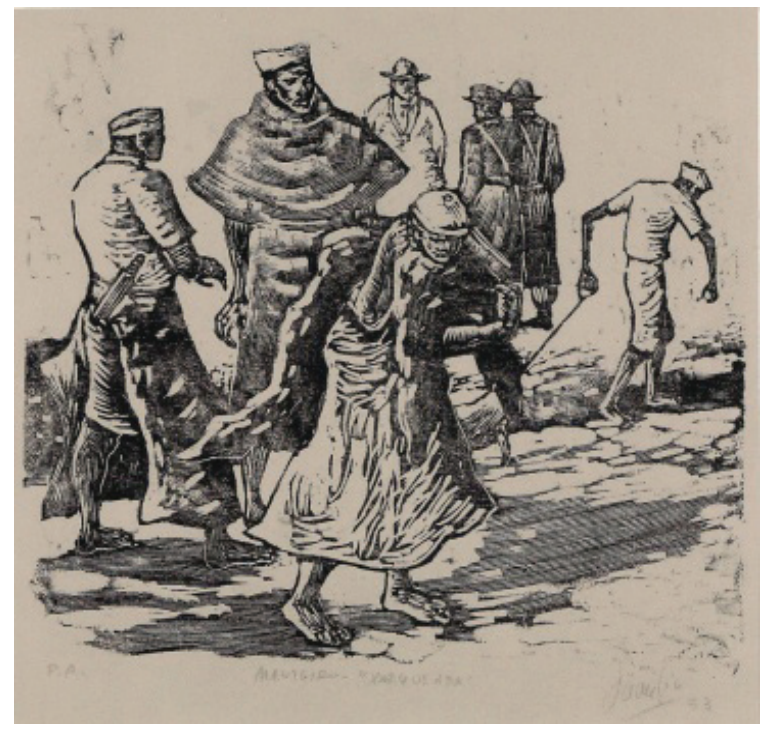

Figura 04 - Danúbio Gonçalves, Manteiros - série Xarqueadas, 1952, Xilogravura, 22x29cm (IMPRESSÕES, 2004, p.72).

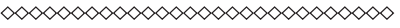

6 "Xilogravura de topo é chamada a gravura feita sobre madeira cortada no sentido transversal ao tronco da árvore" (HERSKOVITZ, 2006, p.63). A madeira de topo é a mais resistente, devido à disposição radial das fibras, fazendo-se necessário o uso de buris para o corte. 


\section{Arte para o povo: houve um desencontro?}

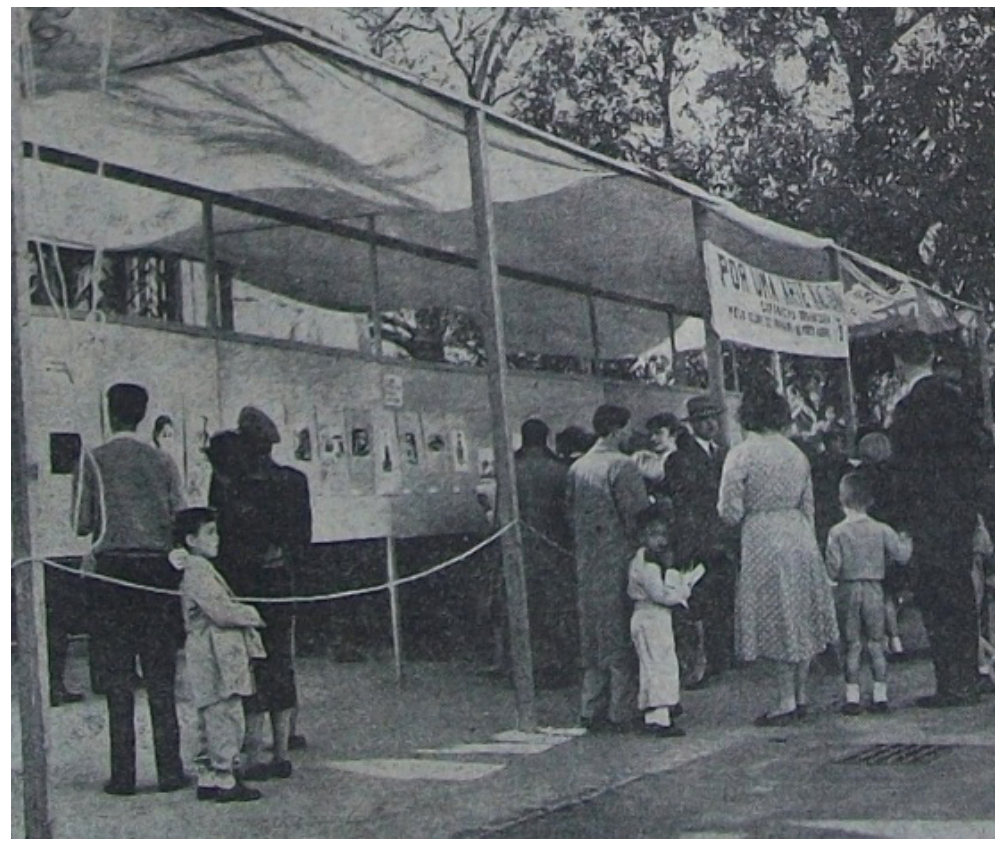

Figura 05 - Fotografia da mostra "Por uma Arte Nacional” (CASTILHOS, 1955, p.12).

No ano de 1955 o CGPA realizou a mostra "Por uma arte nacional" no Parque Farroupilha (Figura 05). A exposição objetivava verificar como o povo percebia as gravuras do Clube, que "se esforçou por uma arte inteligível para as mais amplas camadas populares” (CASTILHOS, 1955, p.12). O visitante, a partir de uma cédula, podia escolher, dentre os 55 trabalhos expostos, quais lhe agradavam mais. O número de quatro mil votos foi extrapolado, e a gravura "Fim de Jornada" de Glênio Bianchetti recebeu o primeiro lugar (SCARINCI, 1955).

A partir dessa experiência e de muitas outras exposições, que foram organizadas pelo Clube de Gravura, além da constante divulgação de sua produção na revista Horizonte, é impossível não concluir que essa agremiação ampliou o público da gravura localmente. Conforme Canclini (1984), um dos critérios para a socialização da arte é a extensão dos consumidores atingidos. A arte para cumprir sua função social necessita do contato com o público e a gravura por seu caráter reprodutível, em que cada impressão, não deixando de ser um original, aumenta os pontos de contato direto com a obra. Segundo Vázquez:

Artista e povo se procuram e não se encontram; algumas vezes - as mais freqüentes - é o povo que o procura e não o encontra; outras 
- nesta sociedade industrial capitalista alienizante -, é o artista que procura o povo sem encontrá-lo. (VÁZQUEZ, 2010, p.254)

Percebe-se a intenção dos artistas do Clube em encontrar o povo, mas, como afirmado anteriormente, a arte popular não é definida pelo número de espectadores. A arte regionalista igualmente não se caracteriza como arte verdadeiramente popular (VÁZQUEZ, 2010), o que permitiria pensar que a temática do gaúcho, verificada nas gravuras do CGPA, implicaria em uma falsa arte popular. Resultado que difere, quando o regional alça ao universal, como na série Xarqueadas de Danúbio Gonçalves. Ainda, sobre as gravuras dos membros do grupo, não se pode dizer que sempre houve uma representação direta de tais temas, sem uma transfiguração do real para fazer uma nova realidade - a obra de arte (VÁZQUEZ, 2010). Nesse novo há explorações de cortes, de texturas e até mesmo de cores, como nas gravuras de Carlos Scliar em que ele utiliza a técnica do pochoir 7 .

Assim, não se pode refutar a tentativa do Clube de Gravura de Porto Alegre de aproximar a arte ao povo, embora os caminhos optados nem sempre levassem a uma arte verdadeiramente popular.

Se as soluções que encontrou são questionáveis, não se pode negar-lhe o mérito de ter despertado uma nova consciência da responsabilidade social e profissional do artista, bem como de criar novas formas para o relacionamento arte e público (SCARINCI, 1982, p.90).

$\infty<\infty<\infty<\infty<\infty<\infty<\infty<\infty<\infty<\infty<\infty<\infty$

7 Pochoir: técnica utilizada para colorir gravuras a partir de estênceis, que limitam as regiões nas quais a tinta é aplicada a mão (HERSKOVITS, 2006). 


\section{Referências bibliográficas}

ALVES, Cauê. Reprodutibilidade e democracia: reflexões sobre o Clube de Gravura do MAM, sua história e o sistema da arte. In: Clube de Gravura: a história do Clube de Colecionadores do MAM. São Paulo: MAM de São Paulo, 2007, p.133-143.

AMARAL, Aracy A. Arte para quê? : a preocupação social na arte brasileira, 19301970: subsídio para uma história social da arte no brasil. 2a ed. São Paulo: Nobel, 1987.

ARANTES, Antonio A. O que é cultura popular. $6^{\mathrm{a}}$ ed. São Paulo: Editora Brasiliense, 1984. (1 $1^{\text {a }}$ ed. 1981$)$

CANCLINI, Néstor G. A socialização da arte: teoria e prática na América Latina. 2a ed. São Paulo: Editora Cultrix, 1984. (1ª ed. 1977, México)

CASTILHOS, Raul. Uma exposição no Parque da Redenção em que o povo foi o juiz. Folha da Tarde, Porto Alegre, 8 out 1955. p. 12-13.

CAVA, Antonio et al. O universo gráfico de Glauco Rodrigues. Rio de Janeiro: Caixa Cultural, 2011. Catálogo de exposição do artista Glauco Rodrigues.

COELHO, Teixeira. Dentro do traço, mesmo. In: . Dentro do traço, mesmo. Porto Alegre: Fundação Iberê Camargo, 2009, p.9-20.

GONÇALVES, Cassandra de C. A. Clube de Gravura de Porto Alegre: Arte e Política na Modernidade. São Paulo: USP, 2005. 163 f. Dissertação (Mestrado em História da Arte) - Programa Interunidades em Estética e História da Arte, USP, São Paulo, 2005.

GRAVURAS Gaúchas: 1950-1952. Rio de Janeiro: Editora Estampa, 1952. Edição especial de 120 exemplares, e edição pela Editora Estampa de 5000 exemplares.

HERSKOVITS, Anico. Xilogravura: arte e técnica. 2. ed. Porto Alegre: Pomar, 2006.

HOLFELDT, Antonio; MORAES, Angélica de; WEBSTER, Maria. H. Grupo de Bagé III - A necessidade de se preservar a vida em todos os lugares e manifestações. Correio do Povo, Porto Alegre, p.15, 18 set. 1976.

IMPRESSÕES: panorama da xilogravura brasileira. Porto Alegre: Santander Cultural, 2004 p.69. Catálogo de exposição com curadoria de Rubem Grilo, período 23 de janeiro a 25 de abril de 2004.

LEITE, José A. M. Xarqueadas de Danúbio Gonçalves: um resgate para a história. $3^{a}$ ed. Porto Alegre: s.c.p, 2011.

PONTUAL, Roberto. Scliar: o real em reflexo e transfiguração. Rio de Janeiro: Civilização Brasileira, 1970.

RIBEIRO, Demétrio. O Salão de Artes Plásticas. Horizonte, Porto Alegre, Nova Fase $\mathrm{n}^{\circ} 10$, p.307, out. 1951 . 
SCARINCI, Carlos. Uma excelente exposição de gravura. Revista do Globo, Porto Alegre, no643, p. 14-15, 23 julho - 5 ago. 1955.

SCARINCI, Carlos. A gravura no Rio Grande do Sul 1900 - 1980. Porto Alegre: Mercado Aberto, 1982.

SCLIAR, Carlos. Das Atividades e Perspectivas Do Clube de Gravura. Horizonte, Porto Alegre, Ano IV n²6, p. 24-25, Jan./Fev. 1954.

SCLIAR, Carlos. Notícias do Clube de Gravura. Horizonte, Porto Alegre, Ano II nº, p.I-VIII, jun. 1952. (encarte especial no interior da revista)

VÁZQUEZ, Adolfo S. As ideias estéticas de Marx. 3ª ed. São Paulo: Expressão Popular, 2010. (1ª ed. 1965, México)

\section{Arquivos}

Arquivo Histórico Moysés Vellinho, Porto Alegre, RS.

Arquivo João Batista Marçal História Operária, Viamão, RS.

Instituto Cultural Carlos Scliar, Cabo Frio, RJ.

Setor de Imprensa do Museu da Comunicação Social Hipólito José da Costa, Porto Alegre, RS. 